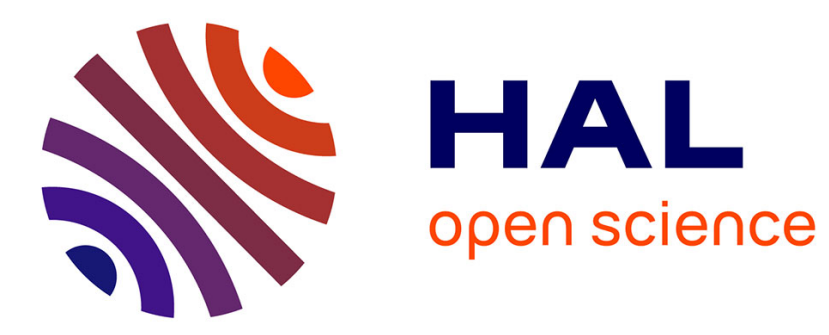

\title{
Integrated electromechanical simulation of traction systems: Relevant factors for the analysis and estimation of energy efficiency
}

G. Boschetti, Andrea Mariscotti

\section{- To cite this version:}

G. Boschetti, Andrea Mariscotti. Integrated electromechanical simulation of traction systems: Relevant factors for the analysis and estimation of energy efficiency. 2012 Electrical Systems for Aircraft, Railway and Ship Propulsion (ESARS), Oct 2012, Bologna, Italy. pp.1-6, 10.1109/ESARS.2012.6387412 . hal-03353441

\section{HAL Id: hal-03353441 \\ https://hal.science/hal-03353441}

Submitted on 24 Sep 2021

HAL is a multi-disciplinary open access archive for the deposit and dissemination of scientific research documents, whether they are published or not. The documents may come from teaching and research institutions in France or abroad, or from public or private research centers.
L'archive ouverte pluridisciplinaire HAL, est destinée au dépôt et à la diffusion de documents scientifiques de niveau recherche, publiés ou non, émanant des établissements d'enseignement et de recherche français ou étrangers, des laboratoires publics ou privés. 


\title{
Integrated Electromechanical Simulation of Traction Systems: Relevant Factors for the Analysis and Estimation of Energy Efficiency
}

\author{
G. Boschetti and A. Mariscotti \\ DITEN - University of Genova \\ Via all'Opera Pia 11A - 16145 Genova - Italy \\ giorgio.boschetti@gmail.com, andrea.mariscotti@unige.it
}

\begin{abstract}
Electromechanical analysis and simulation of traction systems are required to estimate the power consumption, to size the power system and to optimize system parameters for energy saving. The number of variables and parameters (mechanical and electrical) is huge and they are deemed by various degrees of uncertainty. An integrated simulation approach is presented, where some of the major sources of uncertainty are addressed and discussed.
\end{abstract}

Index Terms - Davis equation, Electromechanical simulation, Guideway transportation systems, Model validation.

\section{INTRODUCTION}

Electromechanical simulation of electric transportation systems has several applications: during design, the sizing and rating of electric substations, of traction supply conductors and supply feeders and the optimization of the feeding points, with respect to the maximum absorbed power and the tolerated supply voltage drops along the line; moreover, under major system revamping and modernization, the calculations may be repeated to push optimization even further, reducing power absorption peaks, resizing some feeders and conductors, adjusting the time table and train scheduling. In general, also with the aim of optimizing the power consumption and demonstrating overall system efficiency, electromechanical simulation is a precious tool to support direct measurements.

Electromechanical simulation is a known discipline, in that it results from the combination of mechanical equations of movement of the trains and the electrical network equations, that rule the way the electric power is delivered to the trains at their respective current collection points (called "pantograph" in the following and including also third rail shoe current collection). The first part is normally identified as the mechanical subsystem and the second one is the electrical subsystem.

Electromechanical simulations are normally used during the design of the traction supply network, supporting the sizing of the traction power stations (or substations), the optimization of their separation, the verification of the attainable speed and the correct exploitation of the train characteristics (by monitoring the line voltage). The needed accuracy is in this case around some or several \%, largely covered by the tolerances and the design margins.

On the other hand, when the simulation is used for the evaluation of the overall system energy efficiency, the accuracy required is in the range of a fraction of $\%$. When this figure is applied to the yearly power consumption of a modern electric transportation system, it represents already a tangible difference in terms of money. This translates into a demanding requisite concerning the overall simulator accuracy. Several are the related aspects, but here the focus is on the representation of the two subsystems and the data exchange between the two, in order to ensure an adequate and comprehensive representation of the phenomena.

For the mechanical subsystem both the completeness of the equations and the determination of the parameters and equations coefficients have impact on the accuracy of the estimation of the dragging resistance, or resistance force, $R$. Through the electromechanical traction chain, it is translated into the absorbed electrical power $P_{e l}$. It is underlined then that it is simplistic to assume that the electrical power is delivered to the train only through the fundamental components of the pantograph variables, voltage $V_{p}$ and current $I_{p}$. With a fraction of $\%$ of accuracy as the overall target, the representation must be as sophisticated as possible, in particular where the information on components and parameters is rather complete.

The integrated simulator developed in the last year, and that is used here as a reference for discussion, features thus an electrical subsystem derived from the complete network representation using distributed transmission line equations, and it is believed to be a leap ahead with respect to other solutions based on lumped component simplified network representations. The mechanical subsystem implements the full Armstrong-Swift equations [2], where the coefficients may be derived from available databases. On the contrary the efficiency of the traction chain that translates mechanical power into requested electrical power at pantograph cannot be more accurate than the information supplied by the vehicle or train manufacturer. The interface at the train pantograph is responsible for the iterative 
convergence of $V_{p}$ and $I_{p}$ at each operating point during the simulation.

\section{MEChANICAL SUBSYSTEM}

An electrical transit system in general consists of a combination of a number of trains (or streetcars, or track-free trolley buses), each moving as an independent unit within the general constraints of the operating schedules. All these vehicles are electrically interconnected through the power distribution system (third rail or overhead conductors) fed at specific locations by electrical substations, that in turn draw power from the local utility.

Before the exploitation of regenerative energy and other forms of stored energy, transit vehicles took the entire power for mechanical motion (kinetic energy and drag resistance) as well as on-board auxiliaries and other loads from substations. The introduction of regenerative traction, however, changed the relatively simple scheme of an electrical transit system just considered due to:

- introduction of additional mobile temporary substations, that represents vehicles or trains in regenerative braking;

- need for establishing a maximum line voltage limit.

When considering regenerative braking and the distribution of, the active elements of the power distribution system, the latter are characterized by a variable location (vehicle mobility) and duration of regeneration. In addition, the limitation of the line voltage $V_{\max }$ introduces a major non-linearity: regenerative power is controlled either by switching to an alternative local braking system (dissipative braking) or reducing the amount of regenerative power fed back to the system.

The electrical subsystem solves the electrical network of the traction system at each iteration with movable and fixed lumped sources and loads. The mechanical subsystem implements the modules that calculate time-variable loading (train power draw) and time-variable geometry (train motion). The first point is covered by a step-by-step calculation of the resistance to motion of the train; the latter point is addressed implementing a set of rules that cover vehicle operating conditions and scheduling, timetabling and traffic constraints. In the following both aspects are considered, as well as the main parameters for the calculation of the absorbed power profile, depending on kinetic factors and relative vehicles position and motion.

\section{A. Davis and Armstong-Swift equations}

The train resistance force $R$ is approximated by a quadratic function that is variously known as the "von Borries Formel", the "Leitzmann Formel", the "fonction de Barbier" and, in the Anglo-Saxon world, the "Davis equation" [1]:

$$
R=A+B v+C v^{2}
$$

The coefficients $A$ and $B$ include the mechanical resistances and depend on the train mass, so that at lower speed $(\leq 30 \mathrm{~m} / \mathrm{s}$, that is about $100 \mathrm{~km} / \mathrm{h}$ ) the resistance force $R$ is mainly dependent on the train mass. At higher speed, the $C v^{2}$ term related to the aerodynamic resistance becomes dominant. The values of the coefficients in (1) are usually set for open air conditions and require modification for the tunnel environment, where the $C$ term, in particular, is larger.

Armstrong and Swift [2] proposed a set of empirical expressions to determine the coefficients $A, B$ and $C$ of the Davis equation for the electric multiple units (EMU) in service at that time on the former British Rail lines. The coefficients $A$, $B, C$ in (1) are put in relationship with the following constants:

$$
\begin{gathered}
A=a_{1} m_{T C}+a_{2} m_{P C} \\
B=b_{1} m+b_{2} n_{T C}+b_{3} n_{P C} P \\
C=c_{1} C_{x} S+c_{2} d l+c_{3} d I_{g}\left(n_{T C}+n_{P C}-1\right)+ \\
+c_{4} C_{x}^{B} n_{B}+c_{5} n_{P}
\end{gathered}
$$

where:

$m_{T C}$ in tons is the total mass of trailer cars;

$m_{P C}$ in tons is the total mass of power cars;

$m$ in tons is the train mass;

$n_{T C}$ is the number of trailer cars;

$n_{P T}$ is the number of power cars;

$P$ in $\mathrm{kW}$ is the total power;

$C_{x}$ is the head/tail drag coefficient;

$S$ in $\mathrm{m}^{2}$ is the cross-sectional area;

$d$ in $\mathrm{m}$ is the perimeter;

$l$ in $\mathrm{m}$ is the train length;

$I_{g}$ in $\mathrm{m}$ is the inter-vehicle gap;

$C_{x}^{B}$ is the bogie drag coefficient;

$n_{B}$ is the number of bogies;

$n_{P}$ is the number of pantographs.

The units of the empirical coefficients $a_{1}$ to $c_{5}$ are chosen to results in the correct units for $A, B$ and $C$, e.g. $c_{3}$ is in $\left[\mathrm{N} \mathrm{s}^{2} / \mathrm{m}^{3}\right]$. Armstrong and Swift provide values for $a_{1}$ to $c_{5}$ that lead to the following expression:

$$
\begin{aligned}
A= & 6.4 m_{T C}+8.0 m_{P C} \\
B= & 0.18 m+1 n_{T C}+0.005 n_{P C} P \\
C= & 0.6125 C_{x} S+0.00197 d l+ \\
& +0.0021 d I_{g}\left(n_{T C}+n_{P C}-1\right)+ \\
& +0.2061 C_{x}^{B} n_{B}+0.2566 n_{P}
\end{aligned}
$$

Different authors [1-4] in recent years have described the approaches of various national railway undertakings to the calculation of train resistance. Most of them are empirically modified versions of the Davis equation and include coefficients related to particular types of rolling stock, putting $A, B$ and $C$ in 
relationship with different figures not considered in ArmstrongSwift equations (such as the number of axles and the axle load). This of course adds a further uncertainty contribution including additional terms in the expressions above for the coefficients $A$, $B$ and $C$.

\section{B. Other terms of train resistance force}

In addition to the three friction forces originated by the mass, viscous component of mass and aerodynamic characteristic described by (1), the traction equipment of trains also has to counteract the resistance to acceleration, the gradient force and the curving resistance.

Acceleration is simply a function of the masses with the necessary allowance for the rotating components (also known as "rotary allowance"), while curving is highly dependent on wheel and rail profiles, track cant and the geometry of the vehicle concerned.

\section{Gradient resistance}

The gradient force is mass-related and can be added as an equivalent linear force:

$$
R_{\text {slope }}=m g i
$$

where:

$m$ in $\mathrm{kg}$ is the mass of the train;

$g$ in $\mathrm{m} / \mathrm{s}^{2}$ is the gravity acceleration;

$i$ in $\%$ is the track grade (slope).

The grade $i$ can be expressed as:

$$
i=100 \tan (\alpha)=100 \Delta y / \Delta x
$$

where:

$\alpha$ in $\mathrm{rad}$ is the slope angle;

$\Delta y$ in $\mathrm{m}$ is the rise;

$\Delta x$ in $\mathrm{m}$ is the horizontal run.

Resistance due to track curvature

The curve resistance is an estimate of the added resistance a vehicle has to overcome when operating through a horizontal curve. The exact details of the mechanics contributing to curve resistance are not easy to define. The effects of resistance due to track curvature are small for curves with radius larger than 250 $\mathrm{m}$.

A common formula for calculating the resistance due to track curvature, provided by Profillidis [8], is

$$
r_{c}=0.01\left(\frac{k}{R_{c}}\right)
$$

where:

$r_{c}$ in $\mathrm{kN} / \mathrm{t}$ is the specific resistance force, assuming that the gravity acceleration is $10 \mathrm{~m} / \mathrm{s}^{2}$;

$k$ is a dimensionless parameter, depending on the train design and varying in general from 500 to 1200 ;
$R_{c}$ in $\mathrm{m}$ is the curve radius in a horizontal plane.

However it is generally accepted in the railway industry that the curve resistance is approximately the same as a $0.04 \%$ up grade per degree of curvature for standard gauge tracks [9]. At very slow speed (up to $5 \mathrm{~km} / \mathrm{h}$ ) the curve resistance is closer to $0.05 \%$ up grade per degree of curve.

\section{Operating schedules and timetabling}

To solve the power consumption of the train operation and to investigate the energy efficiency problem, it is necessary to consider the dynamic load behavior of the train set along the route. Trains have allocated time-space slots that are coordinated in a specified timetable and in general in the traffic management rules.

For the scope of this work, it is considered that the timetable takes into account safety issues and main infrastructure constraints (e.g. speed and acceleration limits), while any disturbances (occurring due to unexpected situations caused by unpredicted behavior of infrastructure, trains and staff) are not considered.

For each operation mode, the power demand of the train set can be solved based on the acceleration and train resistance to motion. equation (8) describes the motion equation of a train set:

$$
F_{t}-R_{t}=M_{e q} a
$$

where:

$F_{t}$ in $\mathrm{N}$ is the traction effort;

$R_{t}$ in $\mathrm{N}$ is the total resistance to motion;

$M_{e q}$ in $\mathrm{kg}$ is the equivalent mass of the train set;

$a$ in $\mathrm{m} / \mathrm{s}^{2}$ is the acceleration.

The total resistance to motion can be calculated through the set of equations implemented into the mechanical subsystem, while the train set acceleration is imposed in accordance to vehicles timetabling.

Some of the network infrastructure and trains data needed to characterize the system from the traffic perspective are listed below:

- number of stations and block sections;

- number of line and platforms which are existing in the stations;

- track maintenance periods (section unavailability times);

- length of the block sections;

- train set maximum speed;

- train set priority;

- train dispatching frequency;

- train route in the network;

- train initial departure interval with tolerance;

- section free running time and scheduled stop times;

- safety rules;

- headway times between trains. 


\section{Mechanical subsystem database}

In order to guarantee an efficient data access and data management during the simulation process, data are stored into specific database tables, designed to host with an integrated approach the data required, processed and managed by each simulation module. Of course, this and the electrical database are two views of the same database where the transportation system elements are stored.

\section{Basic Database}

The Basic Database refers to the system data required when the simulator is operating, mainly including line database, traffic database, locomotive database and car database. The abundance of basic data is powerful for the simulator to meet the simulation requirements of different trains and lines. The above databases can be further supplemented or extended by users.

\section{Line Database}

Line Database contains the line geometry and mechanical properties that influence train acceleration and movement trajectory. Examples are gradient values, curvatures, rail type and conditions, tunnel/viaduct/full line, station information, etc..

\section{Trainset Database}

The information in the database is crucial to the electromechanical simulator. The detailed parameters related to locomotives, vehicles, EMUs, train consists and simple cars are provided in the database. Examples of these parameters are identifier, description, weight, length, construction speed, resistance equations coefficients, list of on-board loads, energy efficiency of the various power-train elements, regenerative braking policy and characteristics, etc..

\section{Traffic Database}

It contains all the rules to be implemented (jointly or in alternative) for the circulation on the simulated lines. Examples of criteria are the fulfillment of a timetable, of a speed profile, of acceleration/deceleration constraints. Other criteria that may be implemented beforehand, during the preliminary sizing of the system, are the maximization of the number of passengers in the unit of time or optimization of the origin-destination matrix entries. the predefined train formations are used to achieve the high level of transportation service. To need the transportation service, the locomotives and cars are accordingly chosen from the train formations.

\section{ELECTRICAL SUBSYSTEM}

The electrical subsystem consists of the representation of the electrical network that was adopted in the past using a Multiconductor Transmission Line (MTL) approach, as reported in [10][11] (to exemplify applications to dc, $16.7 \mathrm{~Hz}$ and $50 \mathrm{~Hz}$ systems). The overall set of parameters of the electrical subsystem is very complex and articulated, regarding the perunit-length parameters of conductors and conductor groups [12], the equivalent circuits of electrical equipment and machines (autotransformers, substations - either dc or ac -, impedance bonds, etc.), the inclusion of practical corrections for many configurations and phenomena that would require an impressively increase of the model complexity, going towards finite element techniques and equivalent circuit analysis (effects of viaducts, of buried cables, etc.).

Yet, such a detailed and complete representation of the traction line network is not needed for the purpose of electromechanical simulations, notwithstanding a requirement for the accuracy of the results and of the correct representation of phenomena. The MTL representation mentioned above is being used for interference analysis over a wide frequency range [13][14], and necessitates a simplification before being used for the electromechanical simulation. This is necessary if the difference in length and extension of the line sections taken into account for interference analysis and electromechanical simulation is considered: a few $\mathrm{km}$ for the former, several tens of $\mathrm{km}$, or hundreds of $\mathrm{km}$, for the latter.

What an integrated simulator shall offer is the same input interface and representation for the same object, whatever the actual use in the specific case under study. For this reason not only the electrical and mechanical representations of the line are integrated, with overlapping layers that can be inspected at once and located on a geographical map, but the simplified electrical network for electromechanical simulation shall be (and is) derived automatically from the most complete MTL representation [15].

The requirements for the accuracy of the simplified representation are now briefly reviewed, in the light of the requirements for the pantograph interface. It was decided that during an electromechanical simulation (intended in a wide sense) the following quantities are of interest (maybe, of course, not at the same time): active power at the fundamental, $P_{1}$ (also including dc systems accepting some notation approximations), total active power (including harmonic active power $P_{h}$ ), $P_{t}=P_{1}+P_{h}$, reactive power at the fundamental $Q_{1}$ and total reactive power $Q_{t}$. The term "harmonic" is abused to cover both the harmonics of an ac fundamental, and all the components at frequencies not harmonically related to the fundamental (such as the emissions of on-board dc/dc converters and inverters).

The power exchanged with the traction line by modern rolling stock is only partially located at the system fundamental (either $\mathrm{dc}$ or ac). Traction drives and auxiliaries are characterized by significant conducted emissions; the product of the pantograph voltage and current spectra leads to several active and reactive power terms located on the frequency axis, that represent a significant fraction of the total power and that necessitate adequate modeling of both the line and the source. The former is readily obtained by the MTL formulation, while the latter is related to the models adopted for the rolling stock.

An example follows of the distribution of the power terms for a dc $3 \mathrm{kV}$, a $50 \mathrm{~Hz} 25 \mathrm{kV}$ and a $16.7 \mathrm{~Hz} 15 \mathrm{kV}$ vehicle, based on real measurements. The power supply indexes that are shown 
are the vehicle absorbed active power $P_{1}$ and the pantograph current $I_{1}$ at fundamental, the active harmonic power $P_{h}$ over $P_{1}$ and the total harmonic power $A_{h}$ over the apparent power at fundamental $A_{1}$, the reactive power over apparent power at fundamental $Q_{1} / A_{1}$ and the active power over apparent at harmonics $P_{h} / A_{h}$. The calculations have been performed for each vehicle over long enough time intervals of about 400 to $900 \mathrm{~s}$, experiencing much different operating conditions.

The harmonic content of dc systems is almost always negligible and that the related calculation of power flow at $\mathrm{dc}$ is satisfactory. The considered dc system is a heavy railway system, so with a large supply power with respect to the absorbed power; it is expected that for metro systems the relevance of the largest harmonics is higher. On the contrary, in ac systems, and in particular in $16.7 \mathrm{~Hz}$ systems, the simulation of power flow cannot be done satisfactorily without including also the power terms at harmonic components.


(a)
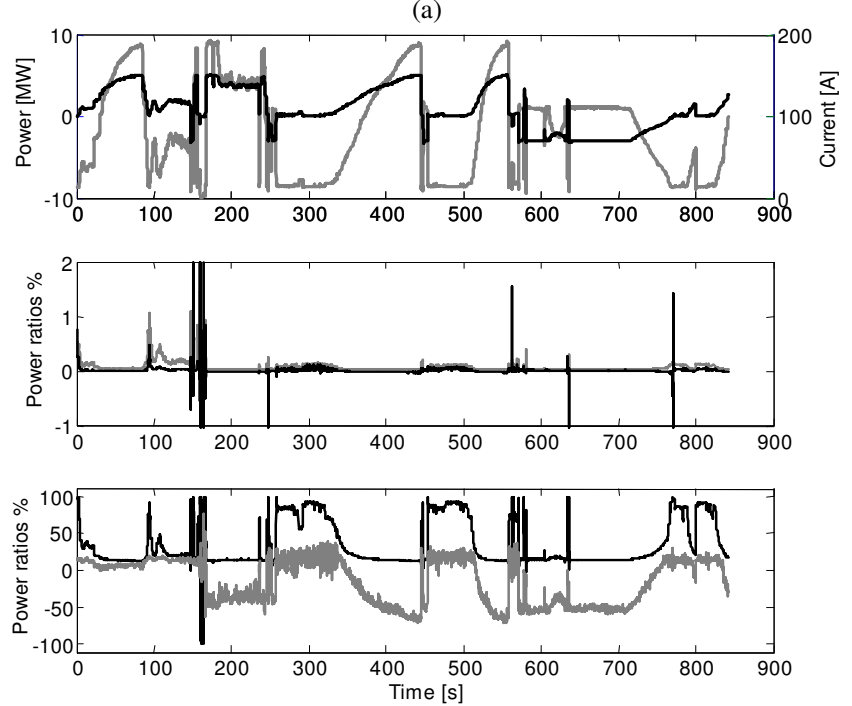

(b)
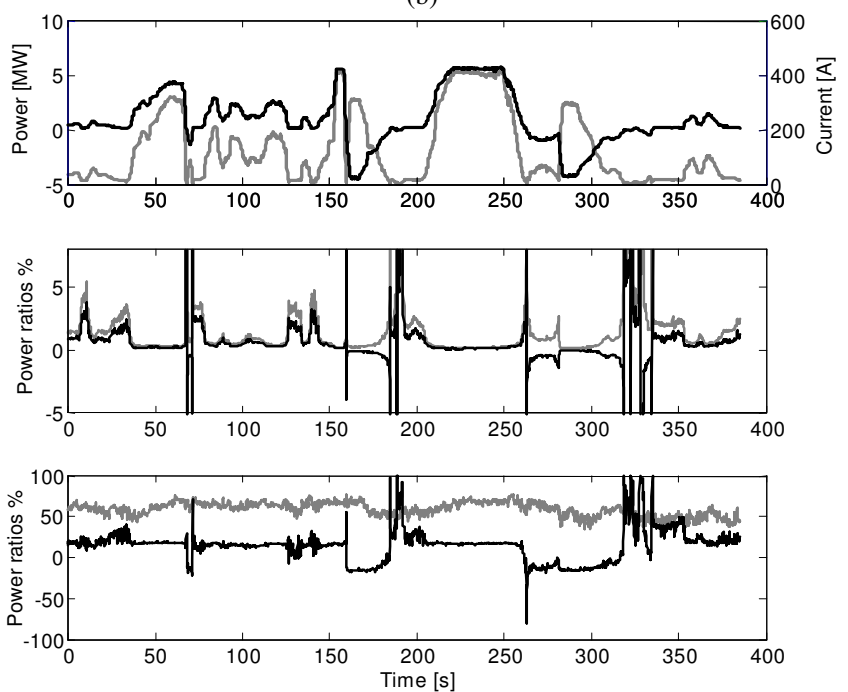

(c)

Figure 1. Power indexes for (a) dc $3 \mathrm{kV}$, (b) $50 \mathrm{~Hz} 25 \mathrm{kV}$ and (c) $16.7 \mathrm{~Hz}$ $15 \mathrm{kV}: \mathrm{P}_{1}$ and $\mathrm{I}_{1}$ (above), $\mathrm{P}_{\mathrm{h}} / \mathrm{P}_{1}$ and $\mathrm{A}_{\mathrm{h}} / \mathrm{A}_{1}$ (middle), $\mathrm{Q}_{1} / \mathrm{A}_{1}$ and $\mathrm{P}_{\mathrm{h}} / \mathrm{A}_{\mathrm{h}}$ (below)

Also the electrical subsystem is to be supported by a database of parameters that are relevant to the determination of electrical parameters. This database contains geometrical data of cross sections, electrical properties of materials (e.g. resistivity, dielectric constant, magnetic permeability, etc.), types of longitudinal connections, etc. Even if the mechanical parameters and the electrical parameters are not so strictly related, so that the two database do not need to be tightly integrated, a certain degree of integration is necessary: it ensures a homogeneous representation of the line, a correspondence to real elements with relevance for both mechanical and electrical aspects.

\section{INDEXES FOR ENERGY EFFICIENCY}

Modern electrified traction systems include switched resistor, regenerative chopper, onboard and wayside energy storage devices. The calculation of energy consumption requires consideration of energy drawn, energy available for return, and energy flows actually occurred between different vehicles for the various operating conditions of the particular transit system. Due to nonlinear characteristics introduced by regenerative traction systems, straightforward average value techniques (similar to those used for sizing substations) cannot be relied upon to generate the average for all cases. It is necessary, therefore, to analyze each transit system operating condition in detail.

The task of enumerating the energy evaluation factors on a per-traction system basis is not straightforward, since the recoverable kinetic energy is a function of various factors: the type and distribution of the other trains and the degree of multiple-route electrical interconnection on a traffic/mechanical level, the impedance at the pantograph, the longitudinal voltage 
drops, the available short circuit power and the allowed voltage rise in the power distribution system.

Considering the energy flows between vehicles - generated by regenerative breaking - the receptivity index can be used to evaluate the energy efficiency of the transit system. The premise here is that receptivity is a measure of the fraction of power available for recovery that, after being subjected to certain necessary constraints, is actually recovered.

Various definitions have been applied to the term receptivity by numerous interested groups [16],[17][18],[19]. Receptivity may be defined in terms of power or energy; calculated either at the substation, train, or traction system; and may be based on a per-streetcar or total-streetcar system calculation.

Here receptivity is defined as the ratio of the braking power actually regenerated to the braking power available for regeneration (also named "recoverable kinetic energy"), calculated at the pantograph level.

To evaluate the receptivity certain characteristics peculiar to regenerative systems must be recognized. The combination of long distance energy transmission and strong interaction between vehicles (energy flow) generally requires a complete and simultaneous simulation of the entire transit system. In addition, the nonlinear characteristics brought out by regeneration preclude the general use of techniques based on averaging of system variables and use of average values. On the contrary, the transit system must be examined over the full range of its operating conditions, considering the mix of loads/sources.

At any instant of time the important parameters for receptivity estimation are:

1) total car power drawn from the supply system;

2) total car power available for return to the supply system;

3 ) total car power actually returned to the supply system.

Vehicle power draw can be calculated as a function of vehicle location and time, considering the system route structure and the physical and electrical characteristics of the vehicles. The recoverable kinetic energy and the power actually recovered depend on the vehicle speed profile at any instance and on the relative location and state (e.g. acceleration, breaking, cruising) of different vehicles moving on the same line.

One solution to the problem consists in adopting the integrated electromechanical simulation approach. Through an adequate set of equations / parameters (as described above), the motion power requested by the vehicles is calculated, while the actually recover power could be estimated from the analysis of transit system operating condition, defined by: 1) vehicle scheduling, 2) vehicle speed profile per mission.

Vehicle speed profile per mission defines at any instant the state of the train and allow to calculate the total power drawn from the supply system. Furthermore the vehicle scheduling (timetable) allows to correlate each vehicle power demand and recoverable kinetic energy with relative location and state of train of other vehicles moving on the same line.
As the receptivity depends on the relative state of train of two or more vehicle on the same line, to reduce the receptivity calculations, vehicle scheduling could be quantified into a discrete number of constant vehicle density cases (e.g., daily rush hour, daily norm, daily evening, and owl) in which the total number of car hours is maintained, and the variation in the total number of cars in the system for each case is acceptably low [19].

\section{CONCLUSIONS}

In the present work an overview of the phenomena and equations related to the mechanical motion of a train are presented. The electromechanical analysis and simulation of traction systems of various kinds (heavy and light railways, metros, etc.) are required to estimate the power consumption and where optimization can be applied more profitably for energy savings. Energy efficiency has been the target of a great research effort all over the world and large traction systems are subject to a huge number of variables (mechanical and electrical), an intrinsic difficulty in the identification of system boundaries and related power flows, and a high degree of uncertainty, in particular on mechanical variables and parameters. Here the sensitivity of the mechanical equations to the set of parameters describing the track and the trains was considered, together with the spread of the output variables for typical variations of the input parameters.

\section{REFERENCES}

[1] B. P. Rochard and F. Schmid, "A review of methods to measure and calculate train resistances", Proceedings of the Institution of Mechanical Engineers, Part F: Journal of Rail and Rapid Transit, vol. 214, no. 4, pp. 185-199, 2000.

[2] D. S. Armstrong and P. H. Swift, "Lower energy technology. Part A, identification of energy use in multiple units. Report MR VS 077, British Rail Research, Derby, 20 July 1990.

[3] R. G. Gawthorpe, "Train drag reduction from simple design changes", International Journal of Vehicle Design, vol. 3, 1983.

[4] P. Lukaszewicz, "Running resistance - results and analysis of full-scale tests with passenger and freight trains in Sweden", Proceedings of the Institution of Mechanical Engineers, Part F: Journal of Rail and Rapid Transit, vol. 221, no. 2, pp. 183-193, 2007.

[5] W. J. Davis, Jr., "The tractive resistance of electric locomotives and cars", General Electric Review, 1926, vol. 29, pp. 2-24.

[6] A. J. Scibor-Rylsky, Road vehicle aerodynamics, London: Pentech Press, 1984.

[7] A. Hammit, Aerodynamic forces on freight trains, Springfield: National Technical Information Services, 1976, vol. I.

[8] V. Profillidis, "Railway Engineering", Avebury Technical: Ashgate Publishing Limited, Aldershot, 1995, pp. 213-224.

[9] AREMA Committee 24, Educational and Training, "Practical Guide To Railway Engineering", AREMA, 2003, pp. 56-62.

[10]A. Mariscotti, "Distribution of the traction return current in AC and DC electric railway systems", IEEE Trans. on Power Delivery, vol. 18 n. 4, Oct. 2003, pp. 1422-1432.

[11]R. Cella, G. Giangaspero, A. Mariscotti, A. Montepagano, P. Pozzobon, M. Ruscelli and M. Vanti, "Measurement of AT Electric Railway System currents and validation of a Multiconductor Transmission Line model", IEEE Trans. on Power Delivery, vol. 21 n. 3, July 2006, pp. 1721-1726. 
[12]A. Mariscotti, P. Pozzobon, "Determination of the Electrical Parameters of Railway Traction Lines: Calculation, Measurement and Reference Data", IEEE Trans. on Power Delivery, vol. 19 n. 4, Oct. 2004 pp. 1538-1546.

[13]A. Mariscotti, "Voltage coupled to wayside interconnecting cables", ESARS 2010, Bologna, IT, Oct. 21-23, 2010.

[14]A. Mariscotti, M. Ruscelli and M. Vanti, "Modeling of Audiofrequency Track Circuits for validation, tuning and conducted interference prediction”, IEEE Trans. on Intelligent Transportation Systems, vol. $11 \mathrm{n}$. 1, March 2010, pp. 52-60.

[15]A. Mariscotti, P. Pozzobon, M. Vanti, "Simplified modelling of $2 \times 25 \mathrm{kV}$ AT Railway System for the solution of low frequency and large scale problems", IEEE Trans. on Power Delivery, vol. 22 n. 1, Jan. 2007, pp. 296-301.

[16]D. R. Phelps, "Assured energy receptivity study-A project overview," Transportation Development Corp., Washington, DC, NTIS Tech. Rep. PB 246-247, Sept. 1975.

[17]Mellitt, B.; Mouneimne, Z.S.; Goodman, C.J.; , "Simulation study of DC transit systems with inverting substations," Electric Power Applications, IEE Proceedings $B$, vol.131, no.2, pp.38-50, March 1984.

[18]Hillmansen, S.; , "Sustainable traction drives," Railway Electrification Infrastructure and Systems, 2009. REIS 2009. 4th IET professional Development Course on, vol., no., pp.255-265, 1-5 June 2009.

[19]Forsythe, James B.; , "Light Rail/Rapid Transit: New Approaches for the Evaluation of Energy Savings, Part II - On the Receptivity of a Transit System," Industry Applications, IEEE Transactions on, vol.IA-16, no.5, pp.665-678, Sept. 1980. 